\title{
Permanent tooth emergence patterns in Dakshina Kannada region, India: an analysis of polymorphisms
}

\author{
Srikant Natarajan ${ }^{1}$, Sharada Chowdappa ${ }^{2}$, Shweta Yellapurkar ${ }^{3 *}$, Karen Boaz ${ }^{3}$, Mithun Pai ${ }^{4}$, D. S. Sriranjani ${ }^{5}$ and \\ Vijendranath Nayak ${ }^{6}$
}

\begin{abstract}
Background: The emergence of permanent teeth in humans starts with the eruption of the permanent mandibular first molar at approximately 6 years of age with the rest of the dentition following a fairly predictable sequence of eruption. The estimation of the age of a child between the ages of 5 and 14 years has so far been facilitated by the adoption of published data/databases that have not always relied on the variations in the sequence of eruption between various populations and ethnicities. The review of literature showed that there are 9 different types of polymorphisms relating to the eruption of teeth.
\end{abstract}

Aim and objectives: The aim of the present study was to estimate the sequence of tooth eruption in children of the Dakshina Kannada region of Southern India and establish/determine the polymorphism in the eruption sequence.

Methods: In this cross-sectional study, 2536 school children of the ages 4-16years were examined for the presence of the permanent teeth. This data was tabulated with their corresponding age and gender. The sequence of eruption was then derived using Probit regression model.

Results: The eruption sequence derived for the maxilla was M1 I1 I2 P1 C P2 M2 and M1 I1 I2 C P1 P2 M2 for the mandible. The maxillary dentition was acquired faster in the females. The mandible showed more number of polymorphisms with 11 M1 type being the most common type of polymorphism. In maxilla P2 C, eruption sequence was interchanged in majority of the studies.

Conclusion: The sequence of emergence of teeth is a population-based variable that shows polymorphism and can be used as an indicator of attainment of a certain age.

Keywords: Probit regression, Sequence of tooth eruption, Eruption polymorphisms

\section{Background}

The emergence of teeth in the upper and lower jaw is considered to be a very consistent timed event that correlates well with the age of the individual. This knowledge of sequence of eruption of teeth is important for the practice of clinical dentistry especially in the branches of pediatrics and orthodontics. The status of the eruption of permanent teeth can also be used as a tool in forensic dentistry. The popularly used developmental chart given by Schour and Massler (sample population not discernible from their publication) gives the

\footnotetext{
* Correspondence: shweta.y@manipal.edu

${ }^{3}$ Department of Oral Pathology and Microbiology, Manipal College of Dental Sciences, Mangalore, Manipal Academy of Higher Education, Mangalore 575001, India

Full list of author information is available at the end of the article
}

general favourable sequence of emergence for permanent dentition as M1, I1, I2, P1, P2, C, M2 and M3 for the permanent maxillary teeth, and M1, I1, I2, C, P1, P2, M2, and M3 for the mandibular permanent teeth (Ash 1996).

The sequence of eruption is affected by environmental factors like nutritional status, fluoride content, and socioeconomic status. Dental caries and premature loss of deciduous teeth (due to trauma, extraction or related disease process) will hasten the eruption of the permanent counterpart. Genetics plays a primary role in determining the growth pattern as evidenced by numerous population-based studies which show variations in the timing of emergence as well as polymorphisms in the eruption sequence. Females in general show faster 
emergence of teeth and gain the full complement of permanent teeth $0.14-0.79$ years ahead of males. In most of the studies, the eruption of the mandibular teeth also occurs ahead of the maxillary teeth (Shaweesh 2012).

The aim of the present study was to evaluate the sequence of emergence of permanent teeth in children of Dakshina Kannada region of Southern India and compare our findings with those from other populations to identify the polymorphisms in eruption sequence.

\section{Materials and methods}

The sample population assessed for this cross-sectional study was from 2536 students (1223 females and 1313 males) aged 4-16 years, attending schools in Dakshina Kannada District, Karnataka, India, that are being provided with community dental care by our dental institution. The study was conducted after obtaining due consent and ethical clearance. The tabulation of age, gender, and dental eruption status was performed on the assumption that all children in the sample group belong to the same geographical region and share a common ancestry and are not racially diverse. The areas of the locations of the schools have not witnessed any significant migration that would have rendered the sample population to be racially diverse.

Dental examination was carried out by trained dental graduates with special attention to the status of eruption of the permanent teeth; a tooth was deemed to have emerged if any portion of the crown was visible through the oral mucosa without further manipulation. The terms eruption and emergence have been synonymously used in the present manuscript to imply natural emergence of the cusp tips of the tooth through the oral mucosa. The third molars were excluded from the study. The age of eruption of the teeth was derived from this data by Probit regression analysis as utilized by Shaweesh (2012). The median age of emergence of a tooth was calculated as the $50 \%$ probability of the tooth being present as per the Probit analysis. SPSS 20.0 was used for statistical analysis.

\section{Results}

The present study had a cohort of 2536 subjects (1223 females and 1313 males) who were evaluated for the presence of emerged teeth. Probit regression analysis was performed with the age rounded to the nearest whole number. Probit analysis considers the time at which $50 \%$ of the teeth have erupted. Based on this, the sequence of eruption of the maxillary and mandibular teeth with mean age of emergence is given in Table 1. The first tooth to erupt in the entire dentition was the mandibular first molar (LM1), and the last tooth to erupt was the maxillary second molar (UM2).

Further, polymorphisms were observed more frequently in the sequence of emergence of mandibular teeth as compared to maxillary teeth. The most common polymorphism seen in the maxillary and mandibular teeth emergence sequence is the eruption of P2-C instead of C-P2 and I1-M1 instead of M1-I1 respectively. Two more frequent polymorphisms noted in the mandibular teeth were eruption of M2 before P2 instead of P2 before M2 and eruption of P1 before $\mathrm{C}$ instead of $\mathrm{C}$ before P1. Table 3 shows the consolidated list of polymorphisms that exist in the maxilla and the mandible.

Table 1 Mean age of emergence as obtained from Probit regression model

\begin{tabular}{|c|c|c|c|c|}
\hline & $\begin{array}{l}\text { Mean age of } \\
\text { eruption in total } \\
\text { sample }\end{array}$ & $\begin{array}{l}\text { Mean age of } \\
\text { eruption in } \\
\text { females }\end{array}$ & $\begin{array}{l}\text { Mean age of } \\
\text { eruption in males }\end{array}$ & $\begin{array}{l}\text { Difference in time (in years) } \\
\text { of eruption between males } \\
\text { and females }\end{array}$ \\
\hline LM1 & 5.88 & 5.63 & 6.14 & 0.52 \\
\hline $\mathrm{LCl}$ & 6.53 & 6.57 & 6.49 & -0.08 \\
\hline LLI & 7.45 & 7.34 & 7.56 & 0.22 \\
\hline LC & 10.32 & 10.12 & 10.52 & 0.40 \\
\hline LPM1 & 10.54 & 10.36 & 10.71 & 0.35 \\
\hline LPM2 & 11.27 & 11.10 & 11.44 & 0.33 \\
\hline LM2 & 11.81 & 11.61 & 12.01 & 0.40 \\
\hline UM1 & 6.12 & 6.00 & 6.24 & 0.24 \\
\hline $\mathrm{UCl}$ & 7.20 & 7.04 & 7.37 & 0.33 \\
\hline ULI & 8.20 & 8.12 & 8.28 & 0.16 \\
\hline UPM1 & 10.43 & 10.32 & 10.55 & 0.23 \\
\hline UC & 10.90 & 10.63 & 11.16 & 0.52 \\
\hline UPM2 & 11.29 & 11.20 & 11.37 & 0.16 \\
\hline UM2 & 12.20 & 12.03 & 12.37 & 0.34 \\
\hline
\end{tabular}




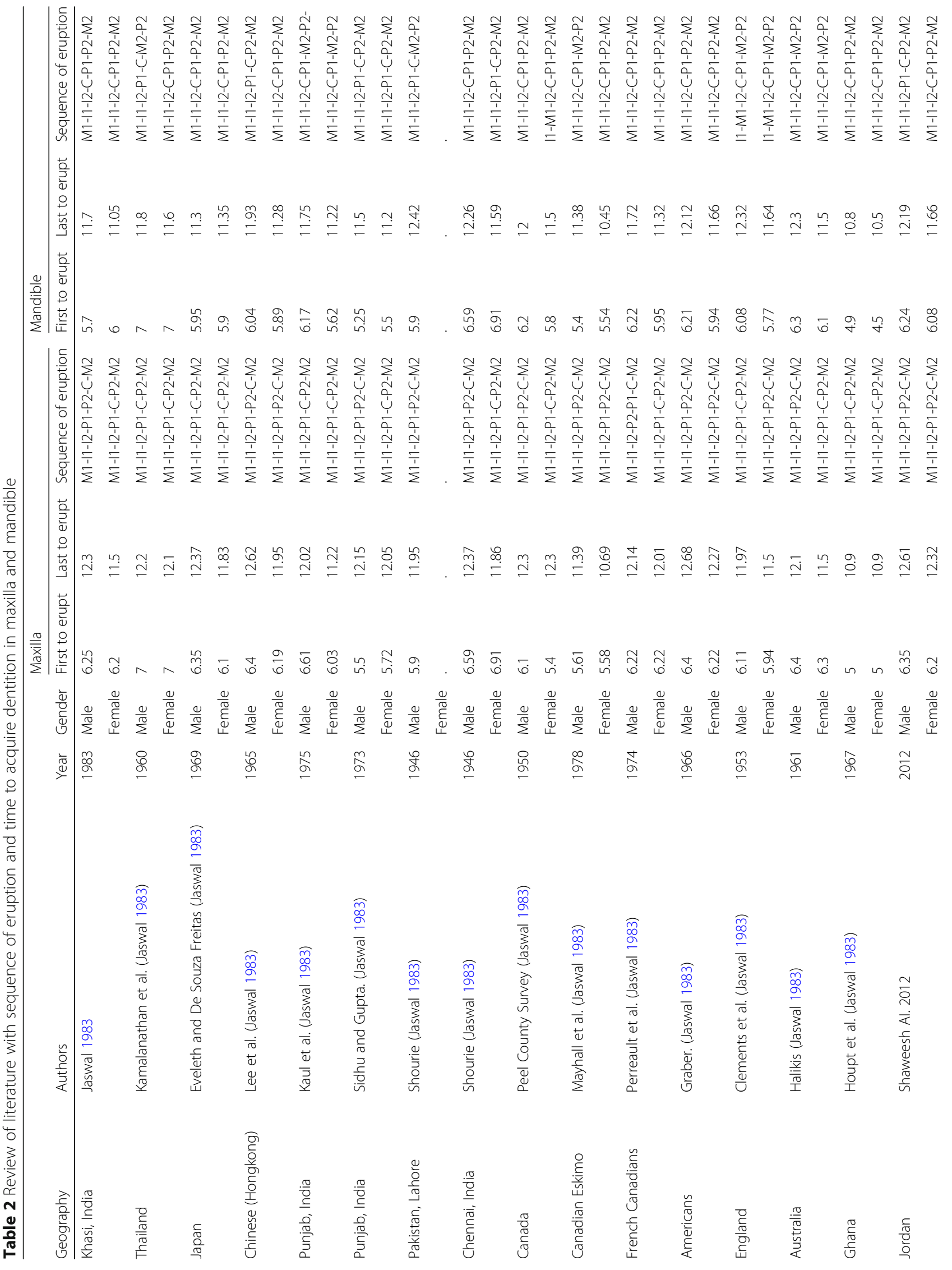




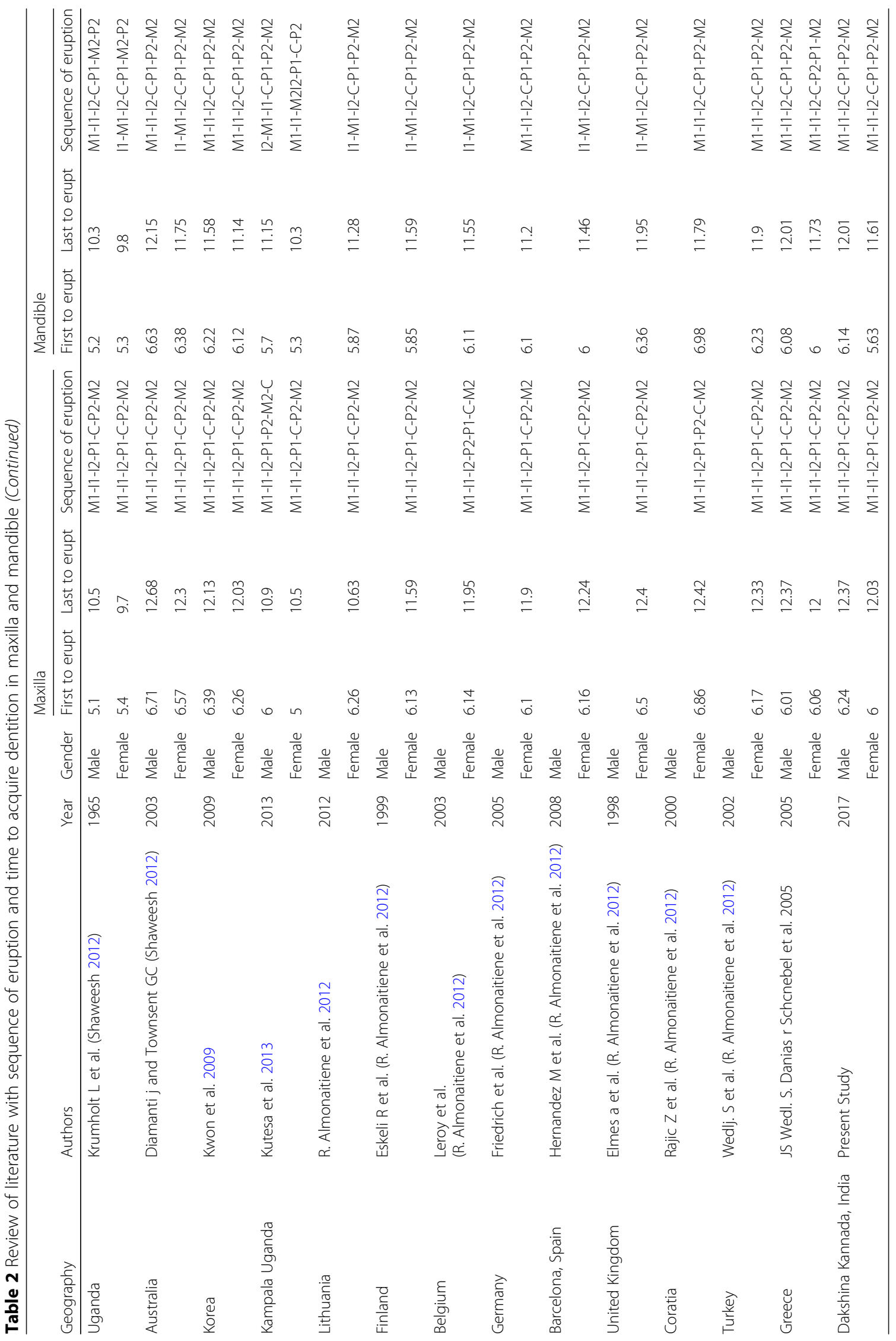




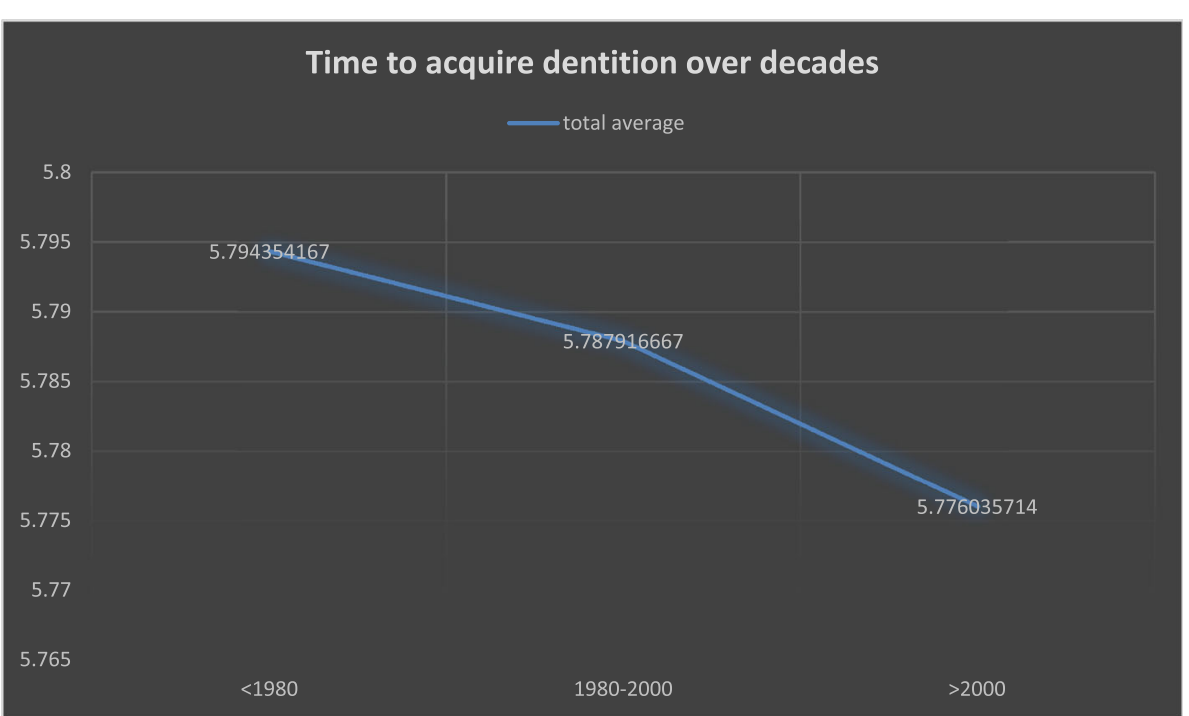

Fig. 1 Time to acquire dentition averaged from the data from Table 1

\section{Discussion}

Tooth eruption is a unique physiological process that originates with tooth development and continues through emergence till a tooth erupts into occlusion with the entire process taking approximately 12-16 years. This vast time period encompasses a host of variables most significantly, physiological (like heredity, constitution, geographic factors, sex, race, nutrition, stress, hormones), pathological systemic factors (systemic diseases and genetic disorders), pathological local factors (local impediments to eruption, hypodontia, lack of space), and the ambient influence of climate and food availability. Several researchers in many areas of the world have studied the eruption patterns. Koch et al. in their textbook have documented that a study in Denmark (from Koch et al. 2009) and Finland (Pahkala et al. 1991) has reported that Caucasians have a delayed time of eruption. Stewart R (1982) suggested that people of Afro-Caribbean lineage have been shown to have an earlier eruption pattern when compared to other ethnic groups (Stewart R. 1982; Ion-Victor et al. 2011).

With a current population of 1.2 billion people, India has been documented as hosting human civilization since at least the 7th millennium BCE. Waves of conquests, wars, and migration added to its ethnic and racial diversity whereby more than 4500 anthropologically

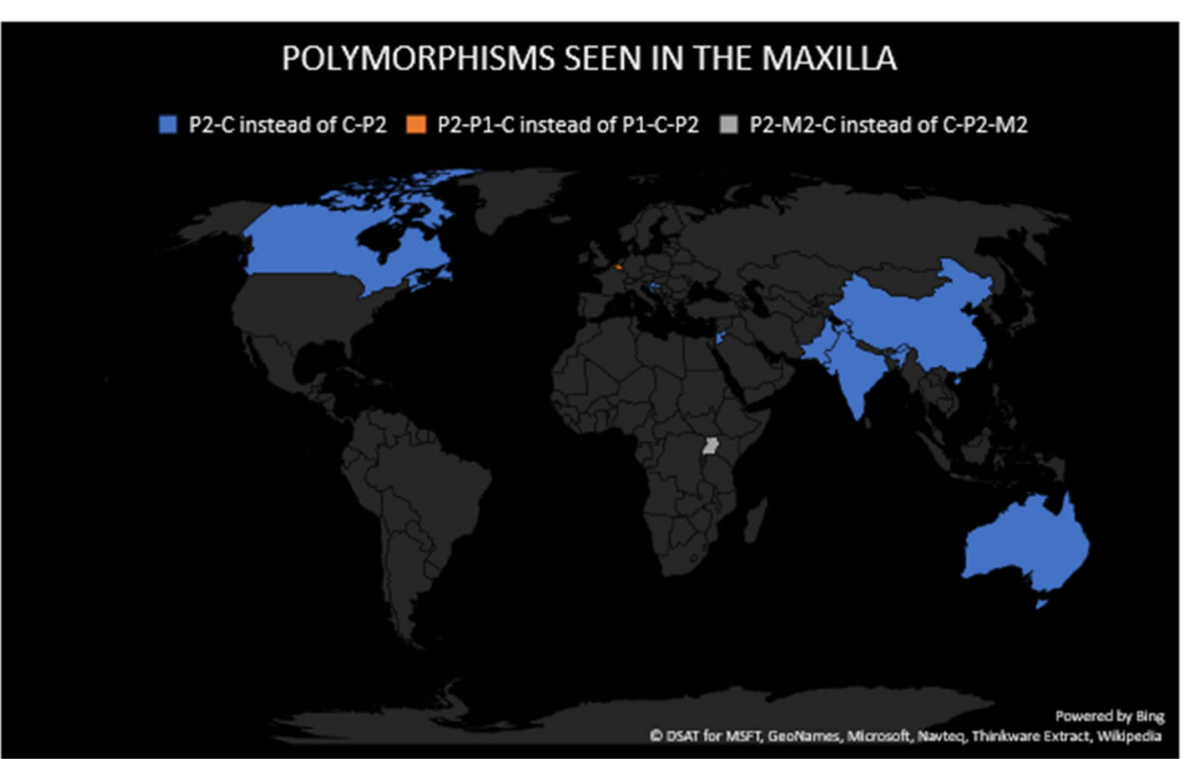

Fig. 2 Polymorphisms seen in the sequence of emergence of maxillary teeth 
defined populations now comprise the Indian populace (Indian Genome Variation Consortium 2005). Having such a heterogenous population contributes to the genomic diversity which may also cause difference in the pattern of tooth emergence.

As students of dentistry, we have been made thorough with the sequence of tooth eruption but are mostly unaware of the existing polymorphisms in the same owing to the paucity of data. These polymorphisms in the sequence of emergence of teeth are important in the estimation of age that has to have near-accuracy in the field of Forensic dentistry. These polymorphisms may also serve as surrogate markers for population-based genetic studies.

While a longitudinal study is ideal in the assessment of the sequence of eruption, it is time consuming and demanding of human and logistic resources. Therefore, cross-sectional studies that calculate the median age, matrix method, maximum likelihood method, Karber's method, ROC curve analysis, and Probit regression method are utilized to determine the sequence of eruption of teeth. The present study employed Probit regression model to derive the sequence of emergence as this is the most common method reportedly used in similar studies previously (Srikant et al. 2015). In one of our previous studies, we have suggested the use of various statistical methods like receiver operator curve characteristics along with Probit analysis to identify these polymorphisms existing in the same population (Srikant et al. 2015).
In the present study, we saw that the mean age of emergence in individuals (irrespective of gender) ranged from approximately 5.88 to 12.20 years. (Table 1 ) The first tooth to erupt was the mandibular first molar (LM1), and the last tooth to erupt was the maxillary second molar (UM2).

Upon review of available relevant literature from 1983 to 2017, it was observed that the sequence of eruption of teeth in humans has remained the same in various populations with the presence of polymorphisms (Table 2). Studies prior to 1980 had reported an average time of acquisition of 5.794 years (2115 days), while studies in the nearly three decades thereafter (from 1980 to 2007) reported a slight decrease to 5.788 years ( 2113 days). Studies after 2000 reported the acquisition time of 5.776 years (2108 days). The time of acquisition of the permanent dentition has therefore hastened by $2-4$ days over 3 decades in the human population (Fig. 1).

This could be attributed to the dietary habits, changing life style, hormones, and various confounding environmental factors (Shaweesh 2012). Rozzi (2016) has reported an early eruption of lower M1 at 3.98 years of age in females and 3.72 years in males in the ethnic Baka people (formerly called the Pygmies). This is much earlier than the other studies reported (Wedl et al. 2005) as well as ours. Kutesa et al. (2013) reported eruption of mandibular and maxillary first molars at age of 5.2 and 5.3 years respectively in an Ugandan Population. Houpt et al. (1967) have also reported early eruption of the mandibular and

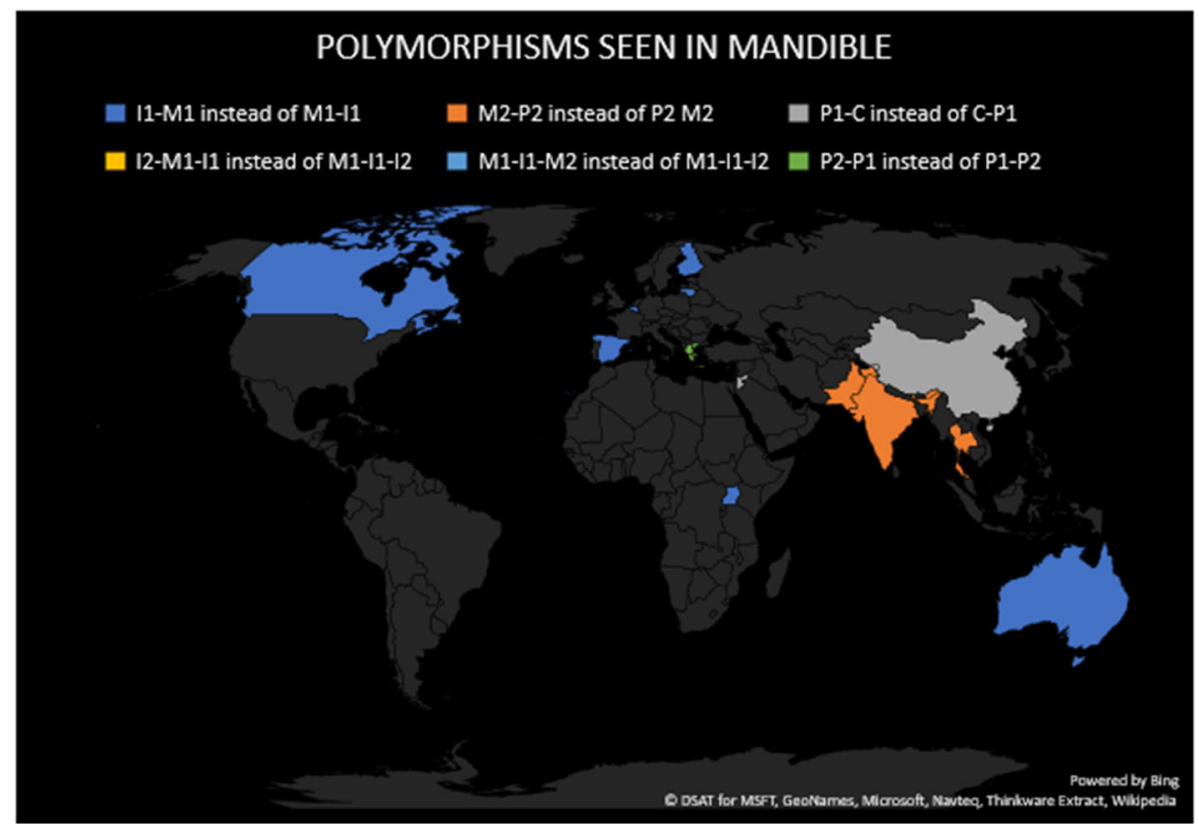

Fig. 3 Polymorphisms seen in the sequence of emergence of mandibular teeth 
maxillary first molar in Brong Ahafo Region of Ghana at 4.4 and 5.0 years respectively.

The eruption of the first permanent molar in the modern human dentition occurs by the age of 6 years. The mandibular teeth erupt before the maxillary teeth and females have an earlier sequence of eruption compared to males. However, the sequence does exhibit polymorphisms (Table 2) that are more

Table 3 Sequence of eruption of maxillary and mandibular teeth with the list of polymorphisms in the eruption seen in different populations

\begin{tabular}{|c|c|c|}
\hline \multicolumn{3}{|l|}{ Maxilla } \\
\hline $\begin{array}{l}\text { Normal sequence of } \\
\text { eruption }\end{array}$ & M1 I1 I2 P1 C P2 M2 & \\
\hline \multirow[t]{3}{*}{ Polymorphisms seen } & $\mathrm{P} 2-\mathrm{C}$ instead of C-P2 & $\begin{array}{l}\text { 1. North India (M) } \\
\text { 2. South India, } \\
\text { Chennai (M) } \\
\text { 3. Chinese (M, F) } \\
\text { 4. Pakistan (M) } \\
\text { 5. Canada (M, F) } \\
\text { 6. England (F) } \\
\text { 7. Australian (M) } \\
\text { 8. Jordan (M, F) } \\
\text { 9. Croatia (F) }\end{array}$ \\
\hline & $\begin{array}{l}\text { P2-P1-C instead of } \\
\text { P1-C-P2 }\end{array}$ & $\begin{array}{l}\text { 1. French Canadian } \\
\text { (M) } \\
\text { 2. Belgium (F) }\end{array}$ \\
\hline & $\begin{array}{l}\text { P2-M2-C instead of } \\
\text { C-P2-M2 }\end{array}$ & 1. Uganda (M) \\
\hline \multicolumn{3}{|l|}{ Mandible } \\
\hline $\begin{array}{l}\text { Normal sequence of } \\
\text { eruption }\end{array}$ & M1 I1 I2 C P1 P2 M2 & \\
\hline \multirow[t]{6}{*}{ Polymorphisms seen } & $\begin{array}{l}\text { I1-M1 instead of M1- } \\
\text { I1 }\end{array}$ & $\begin{array}{l}\text { 1. Canada (F) } \\
\text { 2. England (two } \\
\text { studies) (M, F) } \\
\text { 3. Uganda (F) } \\
\text { 4. Australia (Female) } \\
\text { 5. Lithuania (F) } \\
\text { 6. Finland (F) } \\
\text { 7. Belgium (F) } \\
\text { 8. Spain (F) }\end{array}$ \\
\hline & $\begin{array}{l}\text { M2-P2 instead of P2 } \\
\text { M2 }\end{array}$ & $\begin{array}{l}\text { 1. Thailand (M) } \\
\text { 2. North India (M, F) } \\
\text { 3. Pakistan (M) } \\
\text { 4. Canada (M) } \\
\text { 5. Uganda (M) } \\
\text { 6. Australia (M, F) } \\
\text { 7. England (M, F) }\end{array}$ \\
\hline & $\mathrm{P} 1-\mathrm{C}$ instead of C-P1 & $\begin{array}{l}\text { 1. Chinese (M) } \\
\text { 2. North India (M, F) } \\
\text { 3. South India, } \\
\text { Chennai (F) } \\
\text { 4. Jordan (M) }\end{array}$ \\
\hline & $\begin{array}{l}\text { 12-M1-I1 instead of } \\
\text { M1-11-12 }\end{array}$ & 1. Uganda (M) \\
\hline & $\begin{array}{l}M 1-11-M 2 \text { instead of } \\
M 1-11-12\end{array}$ & 1. Uganda (F) \\
\hline & $\begin{array}{l}\text { P2-P1 instead of P1- } \\
\text { P2 }\end{array}$ & 1. Greece (F) \\
\hline
\end{tabular}

frequently seen in the emergence of mandibular teeth as compared to maxillary teeth (Figs. 2 and 3). The most common polymorphism seen in the maxillary and mandibular teeth emergence sequence is eruption of P2-C instead of C-P2 and I1-M1 instead of M1-I1 respectively. Smith and Garn (1987)) analysed the eruption polymorphisms by preparing matrices of the eruption sequence. They found the P1-C-P2 and M1-I1 sequence to be the most common polymorphism in the maxillary and mandibular arches. They supported the use of square brackets (which was first suggested by Schultz in 1940) to indicate presence of polymorphisms. Accordingly, we should be reporting our sequence as M1 I1 I2 [P1 C P2] M2 for maxilla and [M1 I1] I2 C P1 P2 M2 for mandible. Two other frequent polymorphisms noted in the mandibular teeth were eruption of M2 before P2 instead of P2 before $\mathrm{M} 2$ and eruption of $\mathrm{P} 1$ before $\mathrm{C}$ instead of $\mathrm{C}$ before $\mathrm{P} 1$. This is in accordance with various other studies as listed in Table 3.

\section{Conclusion}

Cognizance of the timing and pattern of tooth eruption are essential for diagnosis, assessment of development of occlusion as well as treatment planning. In the field of forensics, assessment of maturity, age estimation, and comparative odontology requires the knowledge of the normal sequence along with the possible polymorphisms. Studies have shown that eruption patterns coordinate well with the osseous maturity of an individual and the sequence of tooth eruption could be employed for age/gender estimation and comparative dental identification in forensics in individuals in the age range of 5-16 years. The present study has thus reinforced the findings of previous studies on the Indian population that have also shown polymorphism.

\section{Abbreviations}

C: Canine; 11: Central incisor; I2: Lateral incisor; M1: First molar; M2: Second molar; P1: First premolar; P2: Second premolar

\section{Acknowledgements}

Not applicable.

Availability of data and materials

Collection was done from various schools and colleges.

\section{Authors' contributions}

SN was responsible for the data analysis and manuscript writing; SC was responsible for the compilation and manuscript writing. SY was responsible for the compilation and manuscript writing; $\mathrm{KB}$ was responsible for the revision, language correction, and modification of the manuscript; MP was responsible for the data collection; SDS was responsible for the data collection; VN was responsible for the data collection. All authors read and approved the final manuscript.

Ethics approval and consent to participate

Taken from the institutional ethical committee ref no. 


\section{Consent for publication}

Given by all the authors.

\section{Competing interests}

The authors declare that they have no competing interests.

\section{Publisher's Note}

Springer Nature remains neutral with regard to jurisdictional claims in published maps and institutional affiliations.

\section{Author details}

${ }^{1}$ Center for Forensic Odontology, Manipal College of Dental Sciences, Mangalore, Manipal Academy of Higher Education, Mangalore, India. ${ }^{2}$ Mangalore, India. ${ }^{3}$ Department of Oral Pathology and Microbiology, Manipal College of Dental Sciences, Mangalore, Manipal Academy of Higher Education, Mangalore 575001, India. ${ }^{4}$ Department of Public Health Dentistry, Manipal College of Dental Sciences, Mangalore, Manipal Academy of Higher Education, Mangalore, India. ${ }^{5}$ Hyderabad, India. ${ }^{6}$ Department of Oral Medicine and Radiology, AJ Institute of Dental Sciences, Mangalore, India.

Received: 24 November 2017 Accepted: 30 November 2018

Published online: 27 December 2018

\section{References}

Almonaitiene R, Balciuniene I, Tutkuviene J (2012) Standards for permanent teeth emergence time and sequence in Lithuanian children, residents of Vilnius city. Stomatologija 14(3):93-100

Ash, Major M. (ed). 1996. "Wheeler's dental anatomy, physiology and occlusion." Chapter 2: development of teeth, calcification and eruption, 6th Edition, WB Saunders Company, Philadelphia. Pg 24

Houpt MI, Adu-Aryee S, Grainger RM (1967) Eruption times of permanent teeth in the Brong Ahafo region of Ghana. Am J Orthod 53:95-99

Indian Genome Variation Consortium (2005) The Indian Genome Variation database (IGVdb): a project overview. Hum Genet Oct 118(1):1-11

Ion-Victor F, Raducanu AM, Feraru SE, Herteliu C (2011) Sequence and chronology of the eruption of the permanent canines and premolars in Romanian children. Romanian Journal of Oral Rehabilitation 3:37-44

Jaswal S (1983) Age and sequence of permanent tooth emergence among Khasis. Am J Phy Anth 63:177-186

Koch G, Kreiborg S, Andreasen JO (2009) "Eruption and shedding of teeth", in Koch G, Poulsen S, Pediatric dentistry a clinical approach" 2nd edition, Oxford: Wiley-Blackwell publishing. pg. 197-199, ISBN 978-1-4051-6100-8

Kutesa A, Nkamba EM, Muwazi L, Buwembo W, Rwenyonyi CM (2013) Weight, height and eruption times of permanent teeth of children aged 4-15 years in Kampala, Uganda. BMC Oral Health 13:15

Kwon J, Choi B, Lee J, Kim S, Son H, Choi H (2009) Eruption time and sequence of permanent teeth in students from E-elementary school. J Korean Acad Pediatr Dent 36(2):253-261

Pahkala R, Pahkala A, Laine T (1991) Eruption pattern of permanent teeth in a rural community in northeastern Finland. Acta Odontologica Scandinavica 49: $341-349$

Rozzi FR (2016) Diversity in tooth eruption and life history in humans: illustration from a Pygmy population. Sci Rep 6:27405. https://doi.org/10.1038/srep27405

Shaweesh Al (2012) Timing and sequence of emergence of permanent teeth in the Jordanian population. Arch Oral Biol 57:122-130

Smith BH, Garn SM (1987) Polymorphisms in eruption sequence of permanent teeth in American children. Am J Phys Anthropol 74(3):289-303

Srikant N, Sriranjani DS, Boaz K, Pai M, Nayak V, Manaktala N, Nandita KP, Lewis AJ (2015) Receiver operator characteristic curve: a novel technique of assessment of sequence of eruption. J Indian Anthrop Soc 50:39-49

Stewart RE. Pediatric Dentistry: Scientific Foundations and Clinical Practice. St Louis, MO: Mosby; 1982. p. 1027.

Wedl JS, Danias S, Schmelzle R, Friedrich RE (2005) Eruption times of permanent teeth in children and young adolescents in Athens (Greece). Clin Oral Investig 9:131-134

\section{Submit your manuscript to a SpringerOpen ${ }^{\circ}$ journal and benefit from:}

- Convenient online submission

- Rigorous peer review

- Open access: articles freely available online

- High visibility within the field

- Retaining the copyright to your article

Submit your next manuscript at $\boldsymbol{\nabla}$ springeropen.com 